\title{
カーネル密度推定とガウス過程を用いた 非線形・非ガウスシステムの確率的モデリング*
}

\author{
金田 泰昌 ${ }^{\dagger} \cdot$ 鈴木 聡 ${ }^{\dagger} \cdot$ 入月 康晴 ${ }^{\dagger}$

\begin{abstract}
Probabilistic Modeling for Nonlinear and Non-Gaussian
Systems Using Kernel Density Estimation

and Gaussian Process*
\end{abstract}

Yasuaki KANEDA $^{\dagger}$, Satoshi SuzukI ${ }^{\dagger}$ and Yasuharu IRIzukI ${ }^{\dagger}$

\begin{abstract}
Recently, in order to model systems with uncertainty, probabilistic modeling with conditional probability distribution are widely noticed. Modeling the systems as probability density function enables us to apply strategies considering unsertainty to control systems. One of the most famous modeling methods is Gaussian process regression (GPR). GPR is often used in the field of control systems and its effectiveness is demonstrated in many papers. However, since GPR can represent only Gaussian distribution, GPR cannot always achieve good performances for systems under nonGaussian noise. This paper focuses on kernel density estimation that can approximate arbitrary probability distributions and proposes a probabilistic modeling method for non-Gaussian systems including ones with dynamic characteristics. At that time, a proposed method assumes that measurement is written as a sum of noise and function. Moreover, a prior distribution of the function assumes to be Gaussian. Under the assumption, the proposed method estimates the function as hidden variables by variational Bayes methods. The proposed method can model arbitrary probability density function for single output systems from data. Numerical simulations demonstrate the effectiveness of the proposed method.
\end{abstract}

\section{1.はじめに}

近年，不確かさを含むシステムに対して，条件付き確 率を用いた確率的なモデリングが注目されている。シス テムを確率的にモデル化することで不確かさを考慮した 制御方策，たとえば，ノイズに対する不確かさを考慮し た状態推定法であるカルマンフィルタ $[1]$ などが適用で きる。

確率的モデリングの代表的な方法の一つにガウス過程 回帰 (Gaussian process regression: GPR) [2] がある. GPR は関数の事前分布を考え，ベイズ的に予測分布を 求める方法である．観測ノイズの確率分布に加え，関数 の確率分布を陽に考慮することでデー夕に対する関数の 不確かさが評価できる。またノイズも含め，すべての分 布がガウス分布に従うと仮定するため解析的に計算でき る。さらに，共分散行列の設計にカーネルトリックを取

* 原稿受付 2020 年 4 月 15 日

†東京都立産業技術研究センター Tokyo Metropolitan Industrial Technology Research Institute; 2-4-10, Aomi, Koto-ku, Tokyo 135-0064, JAPAN

Key Words: kernel density estimation, Gaussian process, variational Bayes inference.
り入れることで非線形システムの近似が可能となる.

GPRの制御分野への応用例として, 参考文献 [3] では 非線形ガウスシステムの動特性を GPR でモデル化し， そのモデルを非線形カルマンフィルタに応用することで, 陽に記述できないシステムに対する状態推定法が提案さ れている。参考文献 [4] では GPRにより得られたモデ ルをモデル予測制御に適用した方法が提案されており， また参考文献 [5] では GPR を用いたモデル予測制御の 安定性について議論されている。ささらに，参考文献 [6] では GPR を用いた Hamilton-Jacobi不等式の数值的解 法が提案されている。このように，制御分野においても GPR を応用した研究が報告されている。一方，GPRは 非ガウス分布を表現することはできないため，GPR を 非ガウスシステムに対する制御方策に適用しても必ずし も良好な結果は望めない

非ガウスシステムに対する確率的モデリングとして， 観測ノイズモデルに $\mathrm{t}$ 分布を用いた $\mathrm{t}$ 過程が提案されて いる [7]. t 分布はガウス分布に比べ裾の重い分布を表現 できるため，外れ值のような非ガウスノイズを表現でき る.このように, 特定のノイズに対して尤度を変えるこ とで非ガウスノイズがモデル化できる一方，パラメト 
リックな分布を用いて分布形状を仮定する必要がある.

非ガウスシステムに対する別の方法として，カーネル 平均を用いた方法が提案されている [8]. カーネル平均は 確率分布を表現するノンパラメトリック法の一種であり, 分布を再生核ヒルベルト空間に埋め达むことで，グラム 行列を用いた効率的なべイズ推論や理論解析が可能とな る。一方で確率測度が直接的に得られず，ベイズ信用区 間に代表されるべイズ的解釈が容易ではない.

非ガウスシステムに対する別のノンパラメトリックな方 法として, カーネル密度推定 (kernel density estimation: $\mathrm{KDE}$ ）用いて同時分布を近似し，その同時分布から 条件付き密度関数を推定する方法が提案されており. この方法は Nadaraya-Watson (NW) 推定量 [9] とし て知られている。また, 最小二乗法をべースとした条 件付き確率密度推定が提案されており, Least squares conditional density estimation (LSCDE) とよばれてい る [10]. LSCDEは NW 推定量と同様に, 確率密度関数 をカーネル関数の重み付き平均でモデル化する. そして 最小二乗法によりその係数を求める. ガウスカーネルを 用いた場合, LSCDEと NW 推定量は共に同じ構造を もつことが知られている [11]. 両者は任意の確率分布を 推定するためのノンパラメトリック法であり，外れ值を 含め, 複雑な分布形状を表現することができる。 そこで 筆者らはこれらの方法に着目し，これまでに非線形・非 ガウスシステムに対する条件付き確率密度推定法を提案 してきた。 そして, 求めた確率密度関数を粒子フィル夕 (particle filter: PF) [12]に応用することで，ノイズの 事前情報を必要としないPF を提案してきた $[11,13]$. 一 方, これらの方法は GPR とは異なり関数の確率分布を 陽に考慮していないため, 必ずしも関数值の推定精度は 良いとはいえない.

本論文では, 動特性を有する場合も含め, 非線形, 非 ガウスシステムに対して, 分布形状を仮定しない確率的 モデリング法の提案を目的とする。そこで, 確率密度関 数をカーネル関数の重み付き平均でモデル化する方法に 着目する. そして, 関数を陽に考慮するために, 関数值 の予測分布の情報を考慮した条件付き確率密度関数の推 定法を提案する。 そのために, 関数值を隠れ変数とみな し，またその他のモデルパラメータを確率変数とみなす ことで, 得られたデータからパラメータの事後分布を求 める。 そして，その事後分布からシステムの条件付き確 率密度関数を求める。これにより, 得られたモデルのべ イズ的解釈も可能となることが期待される.

本論文の構成は次の通りである. 2. では数学的定義と 問題設定を行う． 3. では既存法である LSCDE と NW 推定量を説明し，両者の関係性を説明する．4.では提案 法としてカーネル密度推定とガウス過程を用いた条件付 き確率密度関数のモデル化とその学習法について説明す る. 5. では数值シミュレーションにて提案法の有効性を 示し， 6. で本論文をまとめる.

\section{2. 準備}

\section{1 定義}

スカラは細字で, ベクトルおよび行列は太字で表す. また, ベクトルの $i$ 番目の要素は $i$ の下添字で, 行列の $(i, j)$ 成分は $i j$ の下添字でそれぞれ表す。たとえば，べ クトル $\boldsymbol{x}$ に対して $i$ 番目の要素は $x_{i}$ と記述し, 行列 $\boldsymbol{A}$ に対して $(i, j)$ 成分は $A_{i j}$ と記述する.

変数および関数が系列番号 $n$ に依存する場合も同様に $n$ の下添字で表す。たとえば, $n$ 番目の系列のベクトル $\boldsymbol{x}$ は $\boldsymbol{x}_{n}$ と表記する. なお, $\boldsymbol{x}_{n}$ の $i$ 番目の要素は $x_{n, i}$ と する。

変数 $s \in \mathbb{R}^{K}$ の各要素が $s_{i} \in\{0,1\}$, かつ $\sum_{i=1}^{K} s_{i}=1$ を満たすとき, $s$ は 1 of $K$ 表現のベクトルとよぶ.

$\boldsymbol{I}$ は単位行列を意味する。

$\langle f(\boldsymbol{x})\rangle_{p(\boldsymbol{x})}$ は確率密度関数 $p(\boldsymbol{x})$ のもとでの $f(\boldsymbol{x})$ の期 待值を表す.すなわち, $\langle f(\boldsymbol{x})\rangle_{p(\boldsymbol{x})}:=\int f(\boldsymbol{x}) p(\boldsymbol{x}) d \boldsymbol{x}$ で ある。

$\mathcal{N}\left(\boldsymbol{x} \mid \boldsymbol{\mu}, \sigma^{2}\right)$ は $\boldsymbol{\mu}$ および $\sigma^{2}$ をパラメータとした正規分 布の確率密度関数であり, 次式で与えられる.

$$
\mathcal{N}\left(\boldsymbol{x} \mid \boldsymbol{\mu}, \sigma^{2}\right):=\frac{1}{\sqrt{2 \pi} \sigma} \exp \left(-\frac{\|\boldsymbol{x}-\overline{\boldsymbol{x}}\|^{2}}{2 \sigma^{2}}\right)
$$

また, 分散の逆数 $\lambda=1 / \sigma^{2}$ は精度とよばれ, 正規分布は 精度を用いて $\mathcal{N}\left(\boldsymbol{x} \mid \boldsymbol{\mu}, \lambda^{-1}\right)$ と表現することもある。

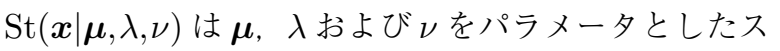
チューデント $\mathrm{t}$ 分布の確率密度関数であり, 次式で与え られる。

$$
\begin{aligned}
& \operatorname{St}(\boldsymbol{x} \mid \boldsymbol{\mu}, \lambda, \nu) \\
& \quad:=\frac{\Gamma\left(\frac{\nu+1}{2}\right)}{\Gamma\left(\frac{\nu}{2}\right)} \sqrt{\frac{\lambda}{\pi \nu}}\left\{1+\frac{\lambda}{\nu}(x-\mu)^{2}\right\}^{-\frac{\nu+1}{2}}
\end{aligned}
$$

ここで, $\Gamma(\cdot)$ はガンマ関数で, 正の実数 $x$ に対して $\Gamma(x):=\int t^{x-1} e^{-t} d t$ で定義される.

$\operatorname{Cat}(\boldsymbol{s} \mid \boldsymbol{\theta})$ は $\boldsymbol{\theta}$ をパラメータとしたカテゴリ分布の確 率密度関数であり, 次式で与えられる。

$$
\operatorname{Cat}(\boldsymbol{s} \mid \boldsymbol{\theta}):=\prod_{i=1}^{N} \theta_{i}^{s_{i}}
$$

ここで, $\theta_{i}>0, \sum_{i=1}^{N} \theta_{i}=1$ であり, $s \in \mathbb{R}^{N}$ は 1 of $N$ 表現のベクトルである.

$\operatorname{Dir}(\boldsymbol{\theta} \mid \boldsymbol{\alpha})$ は $\boldsymbol{\alpha}$ をパラメータとしたデイリクレ分布の 確率密度関数であり, 次式で与えられる。

$$
\begin{gathered}
\operatorname{Dir}(\boldsymbol{\theta} \mid \boldsymbol{\alpha}):=C_{D}(\boldsymbol{\alpha}) \prod_{i=1}^{N} \theta_{i}^{\alpha_{i}-1} \\
\text { ただし }, C_{D}(\boldsymbol{\alpha})=\frac{\Gamma\left(\sum_{i=1}^{N} \alpha_{i}\right)}{\prod_{i=1}^{N} \Gamma\left(\alpha_{i}\right)} \text { である. }
\end{gathered}
$$

$\operatorname{Gam}(\lambda \mid a, b)$ は $a$ および $b$ をパラメータとしたガンマ 
分布の確率密度関数であり, 次式で与えられる.

$$
\operatorname{Gam}(\lambda \mid a, b):=C_{G}(a, b) \lambda^{a-1} \exp (-b \lambda)
$$

ただし， $C_{G}(a, b)=\frac{b^{a}}{\Gamma(a)}$ である.

\section{2 問題設定}

$N$ 個の入出力の組 $\mathcal{D}=\left\{\left(\boldsymbol{x}_{1}, y_{1}\right), \cdots,\left(\boldsymbol{x}_{N}, y_{N}\right)\right\}$ がデー 夕として事前に与えられたとする。ここで， $x_{i} \in \mathbb{R}^{n}$ お よび $y_{i} \in \mathbb{R}$ とする. また, 出力 $y$ は関数 $f(\boldsymbol{x})$ にノイズ $v \in \mathbb{R}$ が加法的に加わるとする.すなわち， $y=f(\boldsymbol{x})+v$ が成り立つとする。 このとき, 入力 $\boldsymbol{x}$ から出力 $y$ までの 条件付き確率密度関数をデータ $\mathcal{D}$ を用いて学習すること を考える.すなわち, 学習モデル $p(y \mid \boldsymbol{x}, \mathcal{D})$ を導出する ことを考える

（注意 1）ノイズ $v$ に関する仮定は加法ノイズである こと以外に何もおいていない，たとえば，ガウスノイズ である必要はなく，非ガウスノイズも対象とする。また 一般には $\mathbb{E}[v]=0$ を仮定することが多いが，本論文では

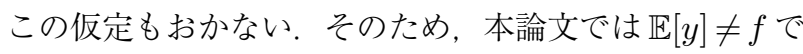
ある。

（注意 2）動特性を有するシステムに関するモデル化に ついて言及する. 状態を $x_{k} \in \mathbb{R}$, 観測值を $y_{k} \in \mathbb{R}$ とする 状態空間モデル $x_{k+1}=f\left(x_{k}\right)+w_{k}, y_{k}=g\left(x_{k}\right)+v_{k}$ を考 える.このとき $x_{k}$ を関数の入力, $y_{k}$ を出力とすることで, 観測モデルに対応した確率的モデル $p\left(y_{k} \mid x_{k}, \mathcal{D}\right)$ を学習す ることができる. 一方, 状態 $x_{k}$ を関数の入力, その 1 ス テップ先の状態 $x_{k+1}$ を出力とすることで, 状態モデルに 対応した確率的モデル $p\left(x_{k+1} \mid x_{k}, \mathcal{D}\right)$ を学習することが できる. また，別のシステムとして外生入力 $u_{k} \in \mathbb{R} を も$ つNARX モデル $y_{k}=f\left(y_{k-1}, \cdots y_{k-n}, u_{k}, \cdots, u_{k-m}\right)+v_{k}$ を考えた場合, $\boldsymbol{x}_{k}:=\left[y_{k-1}, \cdots, y_{k-n}, u_{k}, \cdots, u_{k-m}\right]^{T}$ とす ることでNARX モデル $y_{k}=f\left(\boldsymbol{x}_{k}\right)+v_{k}$ に対応した確率 モデル $p\left(y_{k} \mid \boldsymbol{x}_{k}, \mathcal{D}\right)$ を学習することができる [14].

（注意 3 ） 本論文では入力 $\boldsymbol{x}$ が取得できることを仮定 している。すなわち，参考文献 $[11,13]$ と同様に，状態空 間モデルをモデル化する場合は状態值が取得できること を仮定している。

以降, 簡単のため断りがない限り, 入力 $\boldsymbol{x}$ は省略し, 関数を $f$, 学習モデルを $p(y \mid \mathcal{D})$ とそれぞれ表記する。

\section{3. カーネル関数の重み付き平均による条 件付き確率密度関数の近似法}

\subsection{LSCDE}

学習モデル $p(y \mid \mathcal{D})$ が次式で近似できると仮定する.

$$
p(y \mid \mathcal{D}) \approx \boldsymbol{\theta}^{T} \boldsymbol{\phi}(\boldsymbol{x}, y)
$$

ここで, $\boldsymbol{\phi}(\boldsymbol{x}, y) \in \mathbb{R}^{N}$ は $N$ 個のカーネル関数からなる 基底関数べクトルで, $\boldsymbol{\theta} \in \mathbb{R}^{N}$ はその係数ベクトルであ る.このとき, 次式の評価関数の最小化問題を解くこと
で近似分布 (6) 式の係数を決定する.

$$
J_{0}=\frac{1}{2} \int(p(y \mid \mathcal{D})-p(y \mid \boldsymbol{x}))^{2} p(\boldsymbol{x}) d \boldsymbol{x} d y
$$

$J_{0}$ を展開する際に定数項を無視し, また期待值計算を標 本平均で置き換えると, 次式の評価関数が得られる.

$$
J=\frac{1}{2} \boldsymbol{\theta}^{T} \overline{\boldsymbol{H}} \boldsymbol{\theta}-\boldsymbol{\theta}^{T} \overline{\boldsymbol{h}}
$$

ここで,

$$
\begin{aligned}
& \overline{\boldsymbol{H}}=\frac{1}{N} \sum_{i=1}^{N} \boldsymbol{\Phi}_{i}\left(\boldsymbol{x}_{i}\right), \quad \overline{\boldsymbol{h}}=\frac{1}{N} \sum_{i=1}^{N} \boldsymbol{\phi}\left(\boldsymbol{x}_{i}, y_{i}\right), \\
& \boldsymbol{\Phi}_{i}\left(\boldsymbol{x}_{i}\right)=\int \boldsymbol{\phi}\left(\boldsymbol{x}_{i}, y_{i}\right) \boldsymbol{\phi}^{T}\left(\boldsymbol{x}_{i}, y_{i}\right) d y_{i}
\end{aligned}
$$

参考文献 [10] では計算の簡易さを重視し, 評価関数 (7) 式に対して $L_{2}$ 正則化付き最小二乗法を解き, 負にな る係数を 0 とすることで密度関数の非負性を確保してい る。また, 得られた密度関数を正規化することで次式が 得られる。

$$
p(y \mid \mathcal{D})=\frac{\boldsymbol{\theta}^{T} \boldsymbol{\phi}(\boldsymbol{x}, y)}{\alpha(\boldsymbol{x})}, \alpha(\boldsymbol{x})=\int \boldsymbol{\theta}^{T} \boldsymbol{\phi}(\boldsymbol{x}, y) d y
$$

\section{$3.2 \mathrm{NW}$ 推定量と LSCDE との関係}

データDが与えられたとき，KDEを用いることで同 時分布は次式で近似することができる。

$$
p(\boldsymbol{x}, y \mid \mathcal{D}) \approx \frac{1}{N} \sum_{i=1}^{N} \mathcal{N}\left(\boldsymbol{x} \mid \boldsymbol{x}_{i}, \lambda_{x}^{-1}\right) \mathcal{N}\left(y \mid y_{i}, \lambda_{y}^{-1}\right)
$$

ここで，簡単のため $\boldsymbol{x}$ と $y$ の相互相関がない場合を考え るが，相互相関が存在しても同様に議論できる，このと き，周辺分布 $p(\boldsymbol{x} \mid \mathcal{D})$ は次式で与えられる.

$$
p(\boldsymbol{x} \mid \mathcal{D})=\int p(\boldsymbol{x}, y \mid \mathcal{D}) d y=\frac{1}{N} \sum_{i=1}^{N} \mathcal{N}\left(\boldsymbol{x} \mid \boldsymbol{x}_{i}, \lambda_{x}^{-1}\right)
$$

よって, 条件付き確率密度関数 $p(y \mid \mathcal{D})$ は次式で与えら れる。

$$
\begin{aligned}
p(y \mid \mathcal{D}) & =\sum_{i=1}^{N} \gamma_{i} \mathcal{N}\left(y \mid y_{i}, \lambda_{y}^{-1}\right), \\
\gamma_{i} & =\frac{\mathcal{N}\left(\boldsymbol{x} \mid \boldsymbol{x}_{i}, \lambda_{x}^{-1}\right)}{\sum_{j=1}^{N} \mathcal{N}\left(\boldsymbol{x} \mid \boldsymbol{x}_{j}, \lambda_{x}^{-1}\right)}
\end{aligned}
$$

一方，(8) 式の基底関数がガウスカーネルで与えられた とき, 条件付き確率密度関数は $(9)$ 式と同じ構造となり, また係数 $\gamma_{i}$ は次式で与えられる.

$$
\gamma_{i}=\frac{\theta_{i} \mathcal{N}\left(\boldsymbol{x} \mid \boldsymbol{x}_{i}, \lambda_{x}^{-1}\right)}{\sum_{j=1}^{N} \theta_{j} \mathcal{N}\left(\boldsymbol{x} \mid \boldsymbol{x}_{j}, \lambda_{x}^{-1}\right)}
$$

すなわち, NW 推定量は LSCDEの係数を $1 / N$ にした ものと解釈できる．なお， NW 推定量およびLSCDEに よる出力の期待值は次式で与えられる. 


$$
\langle y\rangle_{p(y \mid \mathcal{D})}=\sum_{i=1}^{N} \gamma_{i} y_{i}
$$

（注意 4） NW 推定量や LSCDE は予測分布がカーネ ルの重み付き平均として与えられると仮定するところか ら議論がはじまっており，ベイズ学習により予測分布を 求めているわけではない，一方，提案法は観測モデルが カーネルの重み付き平均として与えられると仮定し，べ イズ推論を用いて予測分布を導出する。

\section{KDE と GP による条件付き確率密度 関数のモデル化とそのベイズ学習}

\section{1 確率モデルとその尤度}

前節では確率密度関数をカーネル関数の平均で近似す る方法を説明したが，関数值 $f$ はとくに考慮されていな い. 本論文では，関数值 $f$ を陽に考慮した形で，確率密 度関数をカーネル関数の平均で近似する方法を提案する.

ノイズ $v$ の実現值を $v_{i}, i=1, \cdots, N$ とすると, $\mathrm{KDE}$ よりノイズ $v$ の確率密度関数は次式で与えられる。

$$
p(v)=\sum_{i=1}^{N_{K}} \theta_{i} \mathcal{N}\left(v \mid v_{i}, \lambda^{-1}\right), \text { where, } \sum_{i=1}^{N_{K}} \theta_{i}=1
$$

ここで, 一般的な $\mathrm{KDE}$ はカーネル関数の算術平均で与 えられるが，本論文では係数 $\theta_{i}>0$ の重み付き平均で与 えられるとする。いま, $v=y-f$ より，fが与えられた ときの $y$ の確率密度関数は次式となる。

$$
p(y \mid f)=\sum_{i=1}^{N_{K}} \theta_{i} \mathcal{N}\left(y \mid f+v_{i}, \lambda^{-1}\right)
$$

実際には $f や v_{i}, \lambda, \theta_{i}$ は未知パラメータである。そ己 で，各パラメー夕を確率変数とみなし，次式のように条 件として明示する。

$$
p(y \mid f, \boldsymbol{v}, \lambda, \boldsymbol{\theta})=\sum_{i=1}^{N_{K}} \theta_{i} \mathcal{N}\left(y \mid f+v_{i}, \lambda^{-1}\right)
$$

ここで, $\boldsymbol{v}=\left\{v_{1}, \cdots, v_{N_{K}}\right\}, \boldsymbol{\theta}=\left\{\theta_{1}, \cdots, \theta_{N_{K}}\right\}$ である.

次項では，(11) 式に対して, データ $\mathcal{D}$ よりパラメー 夕の事後分布を計算する。事後分布を導出するにあたり， 隠れ変数を用いて (11) 式を積の形に変形する. $s \in \mathbb{R}^{N_{K}}$ を 1 of $N_{K}$ 表現のベクトルとする。このとき，(11) 式 は $s$ を隠れ変数として次式で書き直すことができる.

$$
\begin{aligned}
& p(y \mid f, \boldsymbol{s}, \boldsymbol{v}, \lambda, \boldsymbol{\theta})=\prod_{i=1}^{N_{K}} \mathcal{N}\left(y \mid f+v_{i}, \lambda^{-1}\right)^{s_{i}}, \\
& p(\boldsymbol{s} \mid \boldsymbol{\theta})=\operatorname{Cat}(\boldsymbol{s} \mid \boldsymbol{\theta})
\end{aligned}
$$

実際，両式から $s$ を積分消去することで (11) 式が得られ

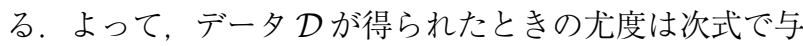
えられる。

$$
\left\{\begin{aligned}
& p(\mathcal{D} \mid \boldsymbol{f}, \boldsymbol{S}, \boldsymbol{v}, \lambda, \boldsymbol{\theta}) \\
&=\prod_{n=1}^{N} \prod_{i=1}^{N_{K}} \mathcal{N}\left(y_{n} \mid f_{n}+v_{i}, \lambda^{-1}\right)^{s_{n, i}} \\
& p(\boldsymbol{S} \mid \boldsymbol{\theta})=\prod_{n=1}^{N} \operatorname{Cat}\left(\boldsymbol{s}_{n} \mid \boldsymbol{\theta}\right)
\end{aligned}\right.
$$

ここで, $\boldsymbol{y}=\left\{y_{1}, \cdots, y_{N}\right\}, \boldsymbol{f}=\left\{f_{1}, \cdots, f_{N}\right\}, \quad \boldsymbol{S}=$ $\left\{s_{1}, \cdots, s_{N}\right\}$ である.

\section{2 変分推論によるパラメータの近似事後分布 の導出}

(12) 式に対して事前分布を次式のように設定する.

$$
\begin{aligned}
p(\boldsymbol{f}) & =\mathcal{N}(\boldsymbol{f} \mid \mathbf{0}, \boldsymbol{K}) \\
p(\boldsymbol{v}, \lambda) & =p(\lambda) \prod_{i=1}^{N_{K}} p\left(v_{i} \mid \lambda\right) \\
p(\boldsymbol{\theta}) & =\operatorname{Dir}(\boldsymbol{\theta} \mid \boldsymbol{\alpha})
\end{aligned}
$$

ここで

$$
p\left(v_{i} \mid \lambda\right)=\mathcal{N}\left(v_{i} \mid \mu_{i},(\beta \lambda)^{-1}\right), \quad p(\lambda)=\operatorname{Gam}(\lambda \mid a, b)
$$

また， $\boldsymbol{K}$ はその $(i, j)$ 成分がカーネル関数 $k\left(\boldsymbol{x}_{i}, \boldsymbol{x}_{j}\right)$ から なるカーネル行列である。すなわち， $f$ はガウス過程に 従い，その平均と共分散は $\mathbf{0}$ および $\boldsymbol{K}$ と仮定している. また， $\mu_{i} ， \beta, a ， b, \boldsymbol{\alpha}$ は各事前分布を決定するハイパー パラメータである。この条件のもと, パラメータの事後 分布 $p(\boldsymbol{f}, \boldsymbol{S}, \boldsymbol{v}, \lambda, \boldsymbol{\theta} \mid \mathcal{D})$ を求める。 ただ, この事後分布 は解析的に求まらないため, 本論文では変分べイズ法を 用いて近似事後分布を導出する。

いま，平均場近似を用いて事後分布を次式で近似する。

$$
p(\boldsymbol{f}, \boldsymbol{S}, \boldsymbol{v}, \lambda, \boldsymbol{\theta} \mid \mathcal{D}) \approx q(\boldsymbol{f}) q(\boldsymbol{S}) q(\boldsymbol{v}, \lambda) q(\boldsymbol{\theta})
$$

ここで，(13) 式の両辺の差を測るために, 次式の KL ダ イバージェンスを定義する.

$$
\begin{aligned}
\mathrm{KL}[q \| p]:= & -\int q(\boldsymbol{f}) q(\boldsymbol{S}) q(\boldsymbol{v}, \lambda) q(\boldsymbol{\theta}) \\
& \times \ln \frac{p(\boldsymbol{f}, \boldsymbol{S}, \boldsymbol{v}, \lambda, \boldsymbol{\theta} \mid \mathcal{D})}{q(\boldsymbol{f}) q(\boldsymbol{S}) q(\boldsymbol{v}, \lambda) q(\boldsymbol{\theta})} d \boldsymbol{f} d \boldsymbol{S} d \boldsymbol{v} d \lambda d \boldsymbol{\theta}
\end{aligned}
$$

このとき, 次の $(14) \sim(17)$ 式で与えられる近似事後分布 の更新を繰り返すことで KL ダイバージェンスを最小化 することができる.

$$
\begin{aligned}
q(\boldsymbol{S}) & =\prod_{n=1}^{N} q\left(\boldsymbol{s}_{n}\right), \quad q\left(\boldsymbol{s}_{n}\right)=\operatorname{Cat}\left(\boldsymbol{s}_{n} \mid \hat{\boldsymbol{\eta}}_{n}\right) \\
q(\boldsymbol{f}) & =\mathcal{N}(\boldsymbol{f} \mid \hat{\boldsymbol{f}}, \hat{\boldsymbol{K}}) \\
q(\boldsymbol{v}, \lambda) & =q(\lambda) \prod_{i=1}^{N_{K}} q\left(v_{i} \mid \lambda\right) \\
q(\boldsymbol{\theta}) & =\operatorname{Dir}(\boldsymbol{\theta} \mid \hat{\boldsymbol{\alpha}})
\end{aligned}
$$

ここで,

$$
q\left(v_{i} \mid \lambda\right)=\mathcal{N}\left(v_{i} \mid \hat{v}_{i},\left(\hat{\beta}_{i} \lambda\right)^{-1}\right)
$$




$$
q(\lambda)=\operatorname{Gam}(\lambda \mid \hat{a}, \hat{b})
$$

また，各事後分布のパラメータは次式で与えられる.

$$
\begin{aligned}
& \hat{\eta}_{n, i} \propto \exp \left(-\frac{\hat{\lambda}}{2}\left\langle\left(y_{n}-f_{n}-v_{i}\right)^{2}\right\rangle_{q\left(f_{n}\right) q\left(v_{i}\right)}\right. \\
& \left.+\frac{1}{2}\langle\ln \lambda\rangle_{q(\lambda)}+\left\langle\ln \theta_{i}\right\rangle_{q(\boldsymbol{\theta})}\right), \\
& \text { where, } \quad \sum_{i=1}^{N_{K}} \hat{\eta}_{n, i}=1 \text {, } \\
& \hat{\boldsymbol{f}}=\hat{\boldsymbol{K}} \overline{\boldsymbol{f}}, \text { where, } \quad \bar{f}_{n}=\hat{\lambda} \sum_{i=1}^{N_{K}} \hat{\eta}_{n, i}\left(y_{n}-\hat{v}_{i}\right) \\
& \hat{\boldsymbol{K}}=\left(\hat{\lambda} \boldsymbol{I}+\boldsymbol{K}^{-1}\right)^{-1} \\
& \hat{v}_{i}=\frac{\sum_{n=1}^{N} \hat{\eta}_{n, i}\left(y_{n}-\hat{f}_{n}\right)+\beta \mu_{i}}{\hat{\beta}_{i}}, \\
& \hat{\beta}_{i}=\sum_{n=1}^{N} \hat{\eta}_{n, i}+\beta, \\
& \hat{a}=\frac{N}{2}+a, \\
& \hat{b}=\frac{1}{2}\left(\sum_{n=1}^{N}\left\langle\left(y_{n}-f_{n}\right)^{2}\right\rangle_{q\left(f_{n}\right)}\right. \\
& \left.+\sum_{i=1}^{N_{K}}\left(\beta \mu_{i}^{2}-\hat{\beta}_{i} \hat{v}_{i}^{2}\right)\right)+b, \\
& \hat{\alpha}_{i}=\sum_{n=1}^{N} \hat{\eta}_{n, i}+\alpha_{i} \\
& \text { ここで， } \\
& \hat{\lambda}=\frac{\hat{a}}{\hat{b}} \\
& \langle\ln \lambda\rangle_{q(\lambda)}=\psi(\hat{a})-\ln \hat{b} \\
& \left\langle\ln \theta_{i}\right\rangle_{q(\boldsymbol{\theta})}=\psi\left(\hat{\alpha}_{i}\right)-\psi\left(\sum_{i=1}^{N_{K}} \hat{\alpha}_{i}\right) \\
& \left\langle\left(y_{n}-f_{n}\right)^{2}\right\rangle_{q\left(f_{n}\right)}=y_{n}^{2}-2 y_{n} \hat{f}_{n}+\hat{f}_{n}^{2}+\hat{K}_{n n} \\
& \left\langle\left(y_{n}-f_{n}-v_{i}\right)^{2}\right\rangle_{q\left(f_{n}\right) q\left(v_{i}\right)} \\
& =\left\langle\left(y_{n}-f_{n}\right)^{2}\right\rangle_{q\left(f_{n}\right)} \\
& -2 \hat{v}_{i}\left(y_{n}-\hat{f}_{n}\right)+\hat{v}_{i}^{2}+\left(\beta_{i} \hat{\lambda}\right)^{-1}
\end{aligned}
$$

ただし, $\psi(\cdot)$ はディガンマ関数であり, $\psi(x):=\frac{d}{d x} \ln \Gamma(x)$ で定義される。なお，近似事後分布の導出は付録を参照 のこと.

\section{3 事後分布を用いた学習モデルの導出}

$(13) \sim(17)$ 式より,

$$
\begin{aligned}
p(\boldsymbol{v}, \lambda, \boldsymbol{\theta} \mid \mathcal{D}) & =\iint_{\mathcal{C}} p(\boldsymbol{f}, \boldsymbol{s}, \boldsymbol{v}, \lambda, \boldsymbol{\theta} \mid \mathcal{D}) d \boldsymbol{f} d \boldsymbol{s} \\
& \approx q(\boldsymbol{v}, \lambda) q(\boldsymbol{\theta})
\end{aligned}
$$

いま，新しい入力 $\boldsymbol{x}_{*}$ に対する関数および出力をそれぞ れ $f_{*}$ および $y_{*}$ とする。 このとき,

$$
\begin{aligned}
& p\left(y_{*} \mid f_{*}, \mathcal{D}\right) \\
& \quad=\iiint p\left(y_{*} \mid f_{*}, \boldsymbol{v}, \lambda, \boldsymbol{\theta}\right) p(\boldsymbol{v}, \lambda, \boldsymbol{\theta} \mid \mathcal{D}) d \boldsymbol{v} d \lambda d \boldsymbol{\theta} \\
& \quad \approx \iiint p\left(y_{*} \mid f_{*}, \boldsymbol{v}, \lambda, \boldsymbol{\theta}\right) q(\boldsymbol{v}, \lambda) q(\boldsymbol{\theta}) d \boldsymbol{v} d \lambda d \boldsymbol{\theta}
\end{aligned}
$$

よって，(11) 式および $(16),(17)$ 式より,

$p\left(y_{*} \mid f_{*}, \mathcal{D}\right)$

$$
\begin{aligned}
= & \sum_{i=1}^{N_{K}} \hat{\theta}_{i} \iint \mathcal{N}\left(y_{*} \mid f_{*}+v_{i}, \lambda^{-1}\right) \\
& \times \mathcal{N}\left(v_{i} \mid \hat{v}_{i},\left(\beta_{i} \lambda\right)^{-1}\right) \operatorname{Gam}(\lambda \mid \hat{a}, \hat{b}) d v_{i} d \lambda \\
= & \sum_{i=1}^{N_{K}} \hat{\theta}_{i} \operatorname{St}\left(y_{*} \mid f_{*}+\hat{v}_{i}, \frac{\hat{\beta}_{i} \hat{a}}{\left(1+\hat{\beta}_{i}\right) \hat{b}}, 2 \hat{a}\right)
\end{aligned}
$$

ここで, $\hat{\theta}_{i}=\left\langle\theta_{i}\right\rangle_{q(\boldsymbol{\theta})}=\frac{\hat{\alpha}_{i}}{\sum_{j=1}^{N_{K} \hat{\alpha}_{j}}}$ である.

最後に $(25)$ 式から $f_{*}$ を消去する. そのため, まず (15) 式より $f_{*}$ の予測分布を求める. $\boldsymbol{f}$ の事前分布の仮定より, $f_{*}$ もまたガウス過程に従う。すなわち, $k_{* *}:=k\left(\boldsymbol{x}_{*}, \boldsymbol{x}_{*}\right)$, $\boldsymbol{k}_{*}:=\left[k\left(\boldsymbol{x}_{*}, \boldsymbol{x}_{1}\right), \cdots, k\left(\boldsymbol{x}_{*}, \boldsymbol{x}_{N}\right)\right]^{T}$ と定義すると次式が成 り立つ.

$$
p\left(\boldsymbol{f}, f_{*}\right)=\mathcal{N}\left(\boldsymbol{f}, f_{*} \mid \mathbf{0},\left[\begin{array}{cc}
\boldsymbol{K} & \boldsymbol{k}_{*} \\
\boldsymbol{k}_{*}^{T} & k_{* *}
\end{array}\right]\right)
$$

ガウス分布の場合, 2 変数の同時分布から条件付き確率密 度関数を解析的に計算することができる [9]. すなわち，

$$
p\left(f_{*} \mid \boldsymbol{f}\right)=\mathcal{N}\left(f_{*} \mid \boldsymbol{k}_{*}^{T} \boldsymbol{K}^{-1} \boldsymbol{f}, k_{* *}-\boldsymbol{k}_{*}^{T} \boldsymbol{K}^{-1} \boldsymbol{k}_{*}\right)
$$

ゆえに，

$$
\begin{aligned}
p\left(f_{*} \mid \mathcal{D}\right) & =\int p\left(f_{*} \mid \boldsymbol{f}\right) p(\boldsymbol{f} \mid \mathcal{D}) d \boldsymbol{f} \\
& \approx \int p\left(f_{*} \mid \boldsymbol{f}\right) q(\boldsymbol{f}) d \boldsymbol{f} \\
& =\mathcal{N}\left(f_{*} \mid \boldsymbol{k}_{*}^{T} \boldsymbol{K}^{-1} \hat{\boldsymbol{f}}, \sigma_{*}^{2}\right)
\end{aligned}
$$

ここで, $\sigma_{*}^{2}=k_{* *}-\boldsymbol{k}_{*}^{T} \boldsymbol{K}^{-1}(\boldsymbol{K}-\hat{\boldsymbol{K}}) \boldsymbol{K}^{-1} \boldsymbol{k}_{*}$ である. $(25),(26)$ 式から $f_{*}$ を積分消去することは困難である. この場合, (26) 式からサンプルされた $M$ 個の実現值 $f_{*}^{(j)}, j=1, \cdots, M$ を用いて, 次式のように予測分布を近 似することができる。

$$
p\left(y_{*} \mid \mathcal{D}\right) \approx \sum_{j=1}^{M} p\left(y_{*} \mid f_{*}^{(j)}, \mathcal{D}\right)
$$

一方, 本論文では簡単のため, (26) 式の平均值を (25) 式 に代入することで学習モデルとする。すなわち,

$$
\begin{aligned}
p\left(y_{*} \mid \mathcal{D}\right):=p\left(y_{*} \mid f_{*}=\left\langle f_{*}\right\rangle_{p\left(y_{*} \mid \mathcal{D}\right)}, \mathcal{D}\right) \\
\quad=\sum_{i=1}^{N_{K}} \hat{\theta}_{i} \operatorname{St}\left(y_{*} \mid \boldsymbol{k}_{*}^{T} \boldsymbol{K}^{-1} \hat{\boldsymbol{f}}+\hat{v}_{i}, \frac{\hat{\beta}_{i} \hat{a}}{\left(1+\hat{\beta}_{i}\right) \hat{b}}, 2 \hat{a}\right)
\end{aligned}
$$

（注意 5）(27) 式は $f_{*}$ を積分消去して得られた分布で はない，そのため，(27) 式はノイズに関する不確かさの 情報を含んでいるが, 関数 $f_{*}$ に関する不確かさの情報 は含んでいない，ただし，関数 $f_{*}$ に関する不確かさは (26) 式を用いて個別に計算することができる.

（注意 6) 提案法では学習で得られた事後分布 (13) 式 のパラメータから一意に学習モデル $(27)$ 式が決まる. 事 後分布の学習では変分推論を用いているため, 繰り返し 計算に比例して学習に必要な計算コストが増える。学習 
後, 学習モデル $(27)$ 式を用いて出力を予測する場合, $N_{k}$ 個の局所 $\mathrm{t}$ 分布の評価が必要となる。たとえば，GPは 一つの正規分布を評価するだけでよいのに対して，提案 法は $N_{k}$ に比例して予測に必要な計算コストが増える。

\section{5. 数值例}

\section{1 疑似データによる提案法の基本性能評価}

\subsection{1 条件}

いま, $v$ を観測ノイズとし，関数 $y=5 \sin (x)+v$ を考 える. そして，データ $\mathcal{D}=\left\{\left(x_{1}, y_{1}\right), \cdots,\left(x_{N}, y_{N}\right)\right\}$ から 確率密度関数 $p(y \mid \mathcal{D})$ を学習する。 ここで, $v$ について 三通りの例を考える。一つめの例は平均 0 , 分散 $0.2^{2}$ の ガウス分布に従うとする. 二つめの例は位置母数 0 , 尺 度母数 0.05 のコーシー分布に従うとする。コーシー分 布は裾の重い分布の一例であり，外れ值のような絶対 值の大きな值が生成される分布である。三つめの例は $0.4 \mathcal{N}\left(v \mid 0.5,0.2^{2}\right)+0.6 \mathcal{N}\left(v \mid-0.5,2 \times 0.2^{2}\right)$ の混合正規 分布に従うとする.

前述したシステムにおいて, GPR と提案法を比較す ることでモデル化精度について比較する。また，LSCDE と提案法を比較することで関数值を陽に考慮した場合の 効果について比較する.

分布を比較する際，一般的にはKLダイバージェンス が用いられる。しかし，KL ダイバージェンスは外れ值 を発生させるような裙の重い分布を比較する際に数值的 に不安定になりやすいことが知られている。 そこで，本 論文では次式のピアソン（Pearson: PE）距離を用いる.

$$
\mathrm{PE}[p \| q]=\int p(\boldsymbol{x})\left(\frac{q(\boldsymbol{x})}{p(\boldsymbol{x})}-1\right)^{2} d \boldsymbol{x}
$$

$\mathrm{PE}$ 距離は KL ダイバージェンスに比べ外れ值にロバス トであることが知られている $[15]$.

使用するデー夕数は $N=N_{K}=600$ とする. GPRの 事前分布で用いるカーネル関数は次式の RBF カーネル とする。

$$
k\left(\boldsymbol{x}_{i}, \boldsymbol{x}_{j}\right)=c_{1} \exp \left(-\frac{1}{2 c_{2}^{2}}\left\|\boldsymbol{x}_{i}-\boldsymbol{x}_{j}\right\|^{2}\right)
$$

そして, 観測ガウスノイズの分散も含めカーネル関数 のパラメータ $c_{1}$ および $c_{2}$ は周辺尤度を最大化すること で求める。一方, 提案法で用いるカーネル関数は, パ ラメータも含めGPR と同じとする。ただし，数值的 な不安定性を回避するために, カーネル行列の対角成 分に微小の值を加える。本数值例では $1.0 \times 10^{-8}$ を加 える。また， $\mu_{i}$ は学習に使用するデー夕 $y_{i}$ を用いて $\mu_{i}=0.1\left(y_{i}-\sum_{i}^{N_{k}} y_{i} / N_{k}\right)$ で与える. そのほか, 提案法 のハイパーパラメータは $(\mathrm{A} 4)$ 式で与えられる ELBO を 最大化する組合せを Table 1 の中から探索する. 変分推論 における繰り返し回数は 200 とする. LSCDEのパラメー 夕は $\lambda_{x}^{-1}, \lambda_{y}^{-1}$ および正則化パラメー夕の三種類であり, 5 -fold 交差検証により $\left\{10^{-3}, 10^{-2}, 10^{-1}, 10^{0}, 10^{1}, 10^{2}\right\}$
Table 1 Candidates of hyper parameters

\begin{tabular}{l|cccc}
$a$ & 1 & 10 & 100 & 1000 \\
$b$ & 1 & 10 & 100 & 1000 \\
$\alpha_{i}$ & 0.01 & 0.1 & 1 & 10 \\
$\beta$ & 0.01 & 0.1 & 1 & 10
\end{tabular}

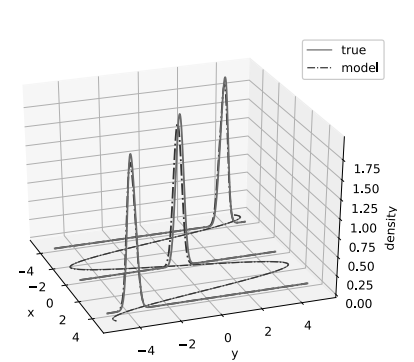

(a) GPR

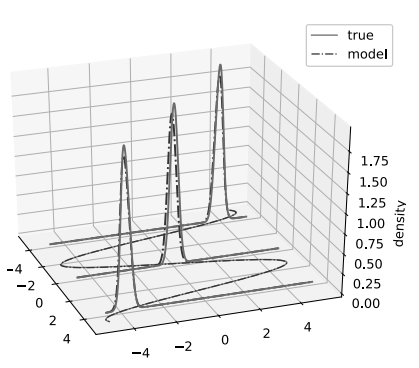

(b) Proposed method
Fig. 1 Measurement models under Gaussian noise learned by (a) Gaussian process regression (GPR) and (b) proposed method, respectively

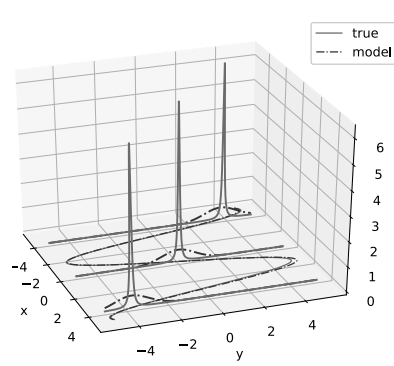

(a) GPR

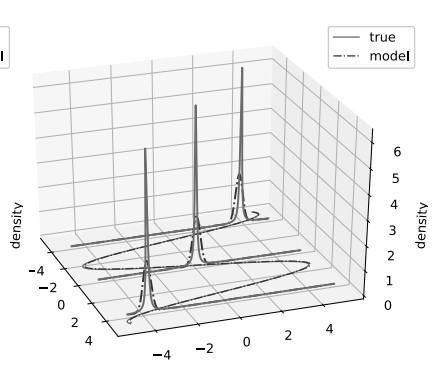

(b) Proposed method
Fig. 2 Measurement models under Cauchy noise learned by (a) Gaussian process regression (GPR) and (b) proposed method, respectively

の中から誤差が最小となる組合せを探索する.

\section{1 .2 近似結果}

Fig. 1 に観測ノイズがガウスノイズの場合のモデル化 結果を示す. 水平面に描かれた曲線が観測モデルの関数 值を示しており, 縦軸方向の曲線は各関数值が与えられ たときの確率密度関数を表す。実線が真值を, 点線が推 定結果を表す。これより, 両者ともに確率密度関数が推 定できていることがわかる.

Fig. 2 に観測ノイズがコーシーノイズの場合のモデル 化結果を示す。この結果より両者ともに関数值は推定で きているが, 分布の推定結果は大きく異なることがわか る. GPR は正規分布で確率密度関数を表現するが, 推 定対象であるコーシー分布は裾の重い分布のため, 分散 が大きな正規分布として推定されている. 一方, 提案法 による予測分布は (27) 式より複数の局所 $\mathrm{t}$ 分布の重ね合 わせで表されており, 局所 $\mathrm{t}$ 分布の密度によって分布が 近似されている. Fig. 3 に, 関数值 $f_{*}=0$ における, 学 習後の局所 $\mathrm{t}$ 分布の中心位置 $\hat{v}_{i}$ を示す。これからもわか るように, コーシーノイズの例では, 学習により分布中 


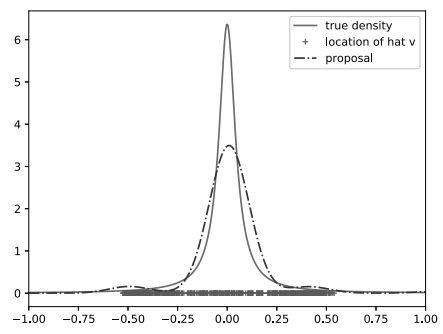

Fig. 3 Locations of central values of local student-t distributions after learning where $a=10000, b=$ $100, \beta=0.001, \alpha=0.01$

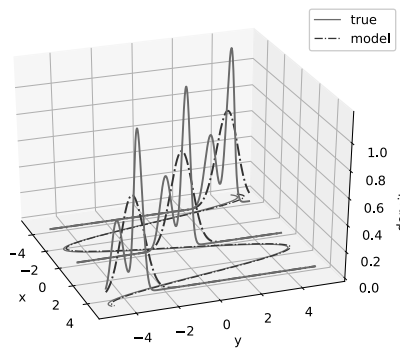

(a) GPR

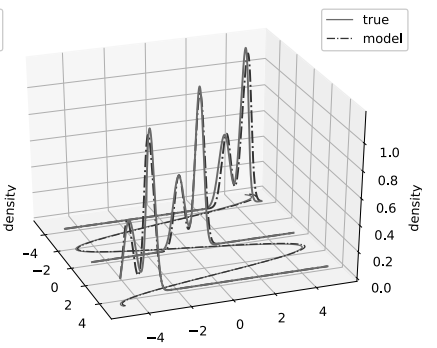

(b) Proposed method
Fig. 4 Measurement models under Gaussian mixture noise learned by (a) Gaussian process regression (GPR) and (b) proposed method, respectively

Table 2 Pearson (PE) distance between true and approximated distributions. Each value is mean and values in brackets are standard deviations of $\mathrm{PE}$ distance at 10 times simulation.

\begin{tabular}{lcc}
\hline & GPR & Proposal \\
\hline Gaussian & $0.069( \pm 0.064)$ & $0.084( \pm 0.073)$ \\
Cauchy & $8.310( \pm 5.303)$ & $1.931( \pm 0.701)$ \\
Gaussian mixture & $2.828( \pm 3.093)$ & $0.329( \pm 0.573)$ \\
\hline
\end{tabular}

央に局所 $\mathrm{t}$ 分布が集中して配置されることで, GPRに比 べて裾の重さに影響されることなく尖度の大きな分布が 近似されている.

Fig. 4 に観測ノイズが混合ガウスノイズの場合のモデ ル化結果を示す。これまで同様，関数值は共に推定でき ていることがわかる。 また，提案法は多峰性の分布を捉 えられていることがわかる。

Table 2 に, 推定した各分布と真の分布との PE 距離 を示す，各值は 10 回計算したときの平均值を表し，括弧 の中の值は標準偏差を表す。この結果より，観測ガウス ノイズが加わっている場合は, GPR と提案法はおおむ ね同等の性能が得られていることがわかる。一方，非ガ ウスノイズが加わっている場合は, 提案法は GPRに比 べ良好な結果が得られていることが定量的にも示されて いる。

Fig. 5 に, 観測ノイズがガウスノイズの場合の, LSCDE によるモデル化結果を示す. GPR や提案法に比べLSCDE

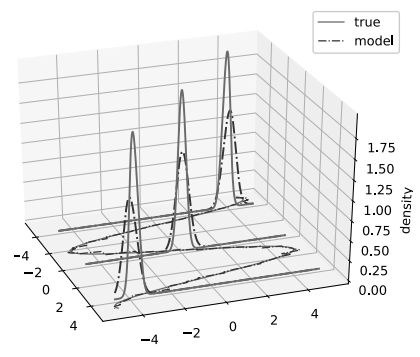

(a) Probability density

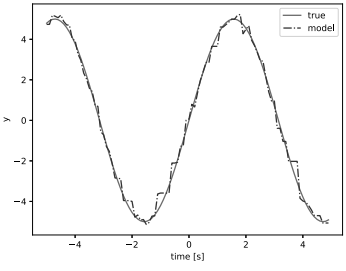

(b) Estimate of function
Fig. 5 Measurement models under Gaussian noise learned by LSCDE. (a) and (b) show estimates of probability density and function " $5 \sin \left(x_{k}\right)$ ", respectively. A mean and standard deviation of $\mathrm{PE}$ distance is 38.04 and 46.31 at 10 times simulation.

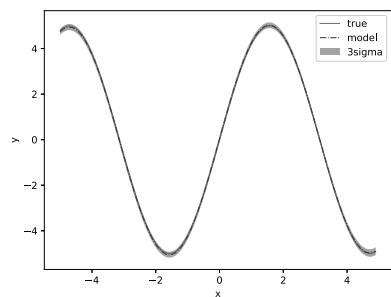

(a) GPR

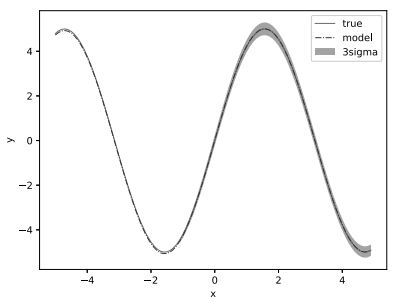

(b) Proposed method
Fig. $6 p\left(f_{*} \mid \mathcal{D}\right)$ under Gaussian noise learned by (a) Gaussian process regression (GPR) and (b) proposed method, respectively

による推定精度は悪いことが確認できる。とくに， LSCDEによる関数の推定值は (10) 式で与えられる 出力の重み付き平均として計算されており, 滑らかな結 果となっていない. 一方, GPR や提案法は関数值のガ ウス過程を考え, カーネルにより関数の滑らかさを制御 することで，LSCDEに比べ滑らかな推定值が得られて いる.

\subsection{3 関数の予測分布の比較}

(26) 式より, GPR 同様, 提案法は関数の予測值 $f_{*}$ の 分布を計算できる。そこで，観測ガウスノイズが加わった 場合の5.1.1の条件と, その条件から $x_{k} \geq 0$ となるデー 夕を削除したときとで, 関数の予測值 $f_{*}$ の分布 $p\left(f_{*} \mid \mathcal{D}\right)$ がどのように計算できるかを比較する。

Fig. 6 に5.1.1 の条件で学習したときの $p\left(f_{*} \mid \mathcal{D}\right)$ を示 す.ここでは $p\left(f_{*} \mid \mathcal{D}\right)$ から標準偏差 $\sigma$ を計算し， $3 \sigma$ で分 布を表現していることに注意する。一方, Fig. 7 に $x_{k} \geq 0$ となるデータを削除したときの $p\left(f_{*} \mid \mathcal{D}\right)$ を示す。これら の結果より, 学習データがない領域では推定精度が悪く なっており，またそれに合わせて $p\left(f_{*} \mid \mathcal{D}\right)$ の分散が大き くなっていることが確認できる. GPR と提案法とで学 習方法に差があるため, 両者の $p\left(f_{*} \mid \mathcal{D}\right)$ は類似している とはいえないが, 学習データがない領域では分布の分散 が大きくなるという性質は一致しているといえる。 


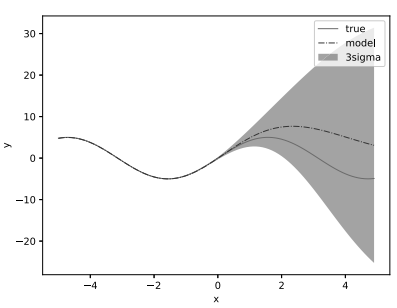

(a) GPR

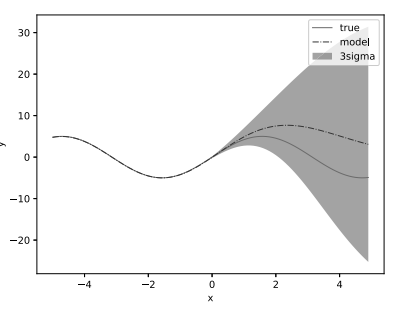

(b) Proposed method
Fig. $7 \quad p\left(f_{*} \mid \mathcal{D}\right)$ under Gaussian noise learned by (a) Gaussian process regression (GPR) and (b) proposed method, respectively. Using limited data results in these models.

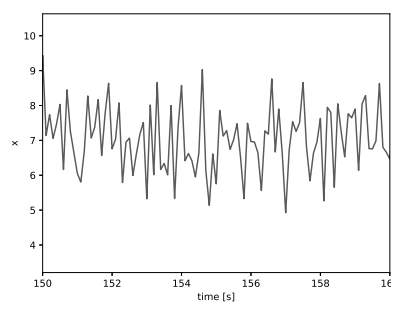

(a) State

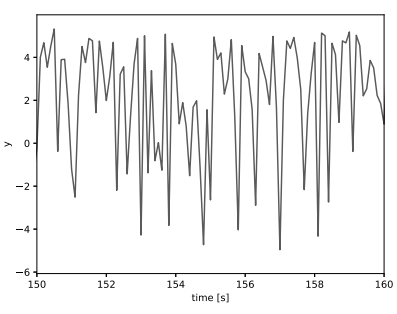

(b) Measurement
Fig. 8 A part of time series data generated from a dynamical system

\section{2 動特性を有するシステムのモデル化}

\subsection{1 条件}

文献 $[16]$ にある以下の離散時間システムを考える.

$$
\begin{aligned}
& x_{k+1}=f\left(x_{k}\right)+w_{k}, \quad y_{k}=g\left(x_{k}\right)+v_{k}, \\
& f\left(x_{k}\right):=\frac{1}{2} x_{k}+\frac{25 x_{k}}{1+x_{k}^{2}}, \quad g\left(x_{k}\right):=5 \sin \left(x_{k}\right)
\end{aligned}
$$

ただし， $w_{k}$ は $\mathcal{N}\left(w_{k} \mid 0,1\right)$ に, $v_{k}$ は $\mathcal{N}\left(v_{k} \mid 0,0.2^{2}\right)$ にそ れぞれ従うとする. このとき, データ $\mathcal{D}_{p}=\left\{\left(x_{i}, x_{i+1}\right)\right\}$, $i=1, \cdots, N$ および $\mathcal{D}_{m}=\left\{\left(x_{i}, y_{i}\right)\right\}, i=1, \cdots, M$ から, 提案法を用いて確率密度関数 $p\left(x_{k+1} \mid x_{k}, \mathcal{D}_{p}\right)$ および $p\left(y_{k} \mid x_{k}, \mathcal{D}_{m}\right)$ を学習する。なお,この節では状態空間 モデルのモデル化を明示するために入力 $x_{k}$ は省略し ない.

Fig. 8 に学習および評価に用いる時系列データの一 部を示す。サンプリング時間は 0.1 秒で, 400 秒までの データのうち, 前半 200 秒までのデータをモデル化用 に, 残り 200 秒分のデータを評価用に使用する．状態お よび観測值のデータはおおむね $5 \leq x_{k} \leq 9,-5 \leq y_{k} \leq 5$ の範囲に集中している。学習に用いるデータはモデ ル化用データから適当な数だけランダムに選択する。 今回は $(N, M)=(1000,600)$ とする. カーネル関数の 設定法は 5.1.1 と同様とし, ハイパーパラメータは $a=b=1, \alpha=\beta=10^{-2}$ とする.

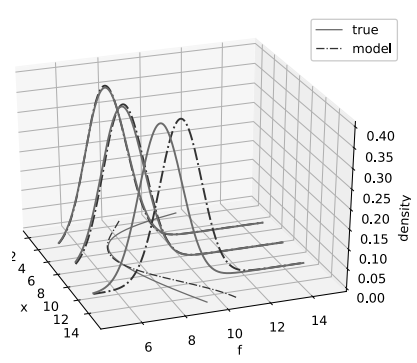

(a) $p\left(x_{k+1} \mid x_{k}, \mathcal{D}_{p}\right)$

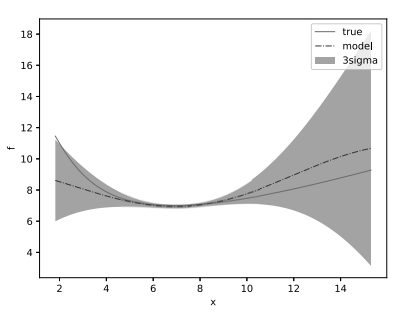

(b) $p\left(f_{*} \mid x_{k}, \mathcal{D}_{p}\right)$
Fig. 9 Learned state model under Gaussian noise. (a) is a predictive distribution and (b) is a probability density function of $f_{*}$.

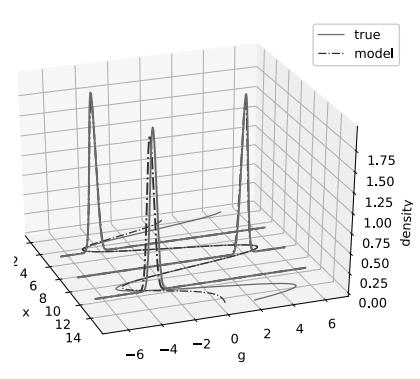

(a) $p\left(y_{k} \mid x_{k}, \mathcal{D}_{m}\right)$

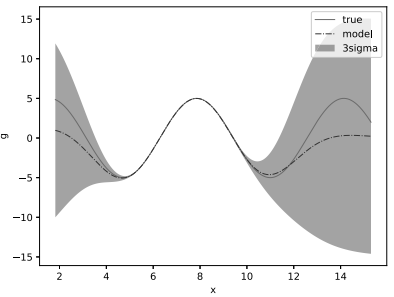

(b) $p\left(g_{*} \mid x_{k}, \mathcal{D}_{m}\right)$
Fig. 10 Learned measurement model under Gaussian noise. (a) is a predictive distribution and (b) is a probability density function of $g_{*}$.

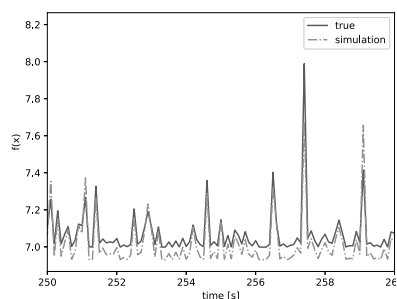

(a) $f\left(x_{k}\right)$

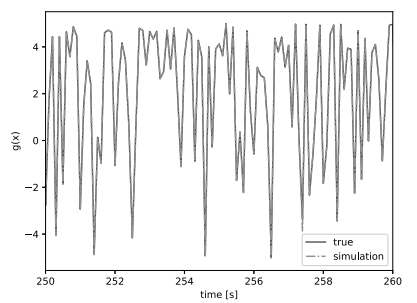

(b) $g\left(x_{k}\right)$
Fig. 11 Simulated results of time series using a learned dynamics. A solid line is a validation data and dashed line is a simulated result.

\subsection{2 結果}

Fig. 9 およびFig. 10 に学習した状態モデルおよび観 測モデルの確率密度関数をそれぞれ示す。また, Fig. 11 に関数 $f\left(x_{k}\right)$ および $g\left(x_{k}\right)$ のシミュレーション結果を示 す.これらの結果より, 学習に用いたデータの範囲にお いてはお拉む真值を再現できていることがわかる。一 方, 学習に用いたデータの範囲外においては関数の真值 との誤差が大きくなり，それに伴い関数の分散が大きく なっていることがわかる.

\section{6. おわりに}

本論文では，モデルの関数值を隠れ変数としてシステ ムの条件付き確率密度関数をモデル化し，隠れ変数を含 
めたパラメータの事後分布を変分ベイズ法を用いて近似 推論する方法を提案した。 そして，その近似事後分布を 用いて，データが与えられたときのシステムの条件付き 確率密度関数を導出した。これにより，動特性を有する 場合も含めて非線形非ガウス系の確率密度関数が学習可 能であることを示した。

今後の課題は, ハイパーパラメータも含めた推論方法 の提案や出力の相互相関を考慮した多出力系（マルチタ スク）への拡張, さらには入力を隠れ変数とし, 出力の みから分布を推論する方法の提案などがある。 また，提 案法では関数がガウス過程に従うと仮定しているが，第 一原理などからあらかじめ関数の構造を決めたうえで, その情報を事前分布に用いることも可能であると考える. この検討も今後の課題の一つと考える.

\section{謝 辞}

本研究は JSPS 科研費 $19 \mathrm{~K} 04450$ の助成を受けたもの である。ここに感謝の意を表する。

\section{参 考文 献}

[1] R. E. Kalman: A new approach to linear filtering and prediction problems; J. Basic Engineering, Vol. 82 , No. 1, pp. 35-45 (1960)

[2] C. E. Rasmussen and C. K. I. Williams: Gaussian Processes for Machine Learning, The MIT Press (2006)

[3] J. Ko and D. Fox: GP-BayesFilters: Bayesian filtering using Gaussian process prediction and observation models; Auton. Robot., Vol. 27, No. 1, pp. 75-90 (2009)

[4] J. Kocijan, R. Murray-Smith, C.E. Rasmussen and A. Girard: Gaussian process model based predictive control; Proc. of 2004 American Control Conference, pp. 2214-2219 (2004)

[5] M. Maiworm, D. Limon, J. M. Manzano and R. Findeisen: Stability of Gaussian process learning based output feedback model predictive control; IFACPapersOnLine, Vol. 51, No. 20, pp. 455-461 (2018)

[6] K. Fujimoto, H. Beppu and Y. Takaki: On computation of numerical solutions to Hamilton-Jacobi inequalities using Gaussian process regression; Proc. of 2018 American Control Conference, pp. 424-429 (2018)

[7] A. Shah, A. G. Wilson and Z. Ghahramani: Student$\mathrm{t}$ processes as alternatives to Gaussian processes; Proc. AISTATS, pp.877-885 (2014)

[8] L. Song, J. Huang, A. Smola and K. Fukumizu: Hilbert space embeddings of conditional distributions with applications to dynamical systems; Proc. ICML, pp. 961-968 (2009)

[9] C. M. Bishop: Pattern Recognition and Machine Learning, Springer (2006)

[10] M. Sugiyama, et al.: Least-squares conditional den- sity estimation; IEICE Trans. Information and Systems, Vol. E93-D, No. 3, pp. 583-594 (2010)

[11] 金田, 入月: データを用いたフィル夕分布の直接推定と 状態推定への応用; 計測自動制御学会論文集, Vol. 53, No. 4, pp. 295-297 (2017)

[12] 樋口: 粒子フィルタ; 電子情報通信学会誌, Vol. 88, No. 12, pp. 989-994 (2005)

[13] 金田, 入月: 確率分布の事前情報を必要としない粒子 フィルタ; システム制御情報学会論文誌, Vol. 32, No. 4, pp. 159-167 (2019)

[14] 山北, 大山: 逐次ガウス過程回帰を用いたロバスト推定 とその応用; システム／制御／情報, Vol. 62, No. 10, pp. 405-410 (2018)

[15] 杉山: 確率分布間の距離推定：機械学習分野における 最新動向; 日本応用数理学会論文誌, Vol. 23, No. 3, pp.439-452 (2013)

[16] M. P. Deisenroth, et al.: Robust filtering and smoothing with Gaussian processes; IEEE Trans. Automat. Contr., Vol. 57, No. 7, pp.1865-1871 (2012)

\section{付 録}

\section{付録 1. 変分推論}

事後分布 $p(\boldsymbol{z} \mid \mathcal{D})$ を $q(\boldsymbol{z})$ で近似するために, 次式の $\mathrm{KL}$ ダイバージェンスを最小化する $q$ を求める.

$$
\mathrm{KL}[q \| p]=-\int q(\boldsymbol{z}) \ln \frac{p(\boldsymbol{z} \mid \mathcal{D})}{q(\boldsymbol{z})} d \boldsymbol{z}
$$

いま， $q$ に対して平均場近似を考える。すなわち， $z$ の要素を $N$ 個の排他的なグループ, $\boldsymbol{z}_{1}, \cdots, \boldsymbol{z}_{N}$, に分割 し, 次式のように各確率変数に独立性の仮定をおく.

$$
q(\boldsymbol{z})=\prod_{i=1}^{N} q\left(\boldsymbol{z}_{i}\right)
$$

$i$ 番目の確率変数 $\boldsymbol{z}_{i}$ を除いた集合を $\boldsymbol{z}_{\backslash i}$ とする.この とき， $q\left(\boldsymbol{z}_{\backslash i}\right)$ が固定されたもとで $(\mathrm{A} 1)$ 式を最小にする $q\left(\boldsymbol{z}_{i}\right)$ は次式で与えられる.

$$
\ln q\left(\boldsymbol{z}_{i}\right)=\langle p(\boldsymbol{z}, \mathcal{D})\rangle_{q\left(\boldsymbol{z}_{\backslash i}\right)}+C
$$

ここで, $C$ は定数を表す，すなわち, $q\left(\boldsymbol{z}_{i}\right)$ の対数は, 同 時分布の対数を考え, $\boldsymbol{z}_{i}$ 以外の確率変数についての期待 值を計算したものと等しくなる $[9]$.

なお, (A1) 式より次式が成り立つ.

$$
\begin{aligned}
\mathrm{KL}[q \| p] & =-\int q(\boldsymbol{z}) \ln \frac{p(\boldsymbol{z}, \mathcal{D})}{q(\boldsymbol{z})} d \boldsymbol{z}+\ln p(\mathcal{D}) \\
& =:-\mathcal{L}[q]+\ln p(\mathcal{D}) \geq 0
\end{aligned}
$$

よって, $\mathcal{L}[q]$ は対数周辺尤度 $\ln p(\mathcal{D})$ の下限であること がわかり，この值を Evidence lower bound (ELBO) と よぶ. 対数周辺尤度は $q$ に依存しないため, $\mathrm{KL}[q \| p]$ を $q$ に関して最小化することは, ELBOを $q$ に関して最大 化することと等価である. 
付録 2. $q(\boldsymbol{S})$ の導出

$\boldsymbol{S}$ の項以外は定数とみなすと (A2) 式より,

$$
\begin{aligned}
& \ln q(\boldsymbol{S})=\langle\ln p(\boldsymbol{y} \mid \boldsymbol{f}, \boldsymbol{S}, \boldsymbol{v}, \lambda)\rangle_{q(\boldsymbol{f}) q(\boldsymbol{v}, \lambda)}+\langle\ln p(\boldsymbol{S} \mid \boldsymbol{\theta})\rangle_{q(\boldsymbol{\theta})}+C \\
&=\sum_{n=1}^{N}\left(\left\langle\ln p\left(y_{n} \mid f_{n}, \boldsymbol{s}_{n}, \boldsymbol{v}, \lambda\right)\right\rangle_{q\left(f_{n}\right) q(\boldsymbol{v}, \lambda)}\right. \\
&\left.+\left\langle\ln p\left(\boldsymbol{s}_{n} \mid \boldsymbol{\theta}\right)\right\rangle_{q(\boldsymbol{\theta})}\right)+C
\end{aligned}
$$

これは $s_{n}$ に関して和の形式になっており, 各変数ごとの 独立な分布に分解できることを意味する.よって, $q\left(\boldsymbol{s}_{n}\right)$ に関して考えると,

$$
\begin{array}{r}
\ln q\left(\boldsymbol{s}_{n}\right)=\sum_{i=1}^{N_{k}} s_{n, i}\left(-\frac{\hat{\lambda}}{2}\left\langle\left(y_{n}-f_{n}-v_{i}\right)^{2}\right\rangle_{q\left(f_{n}\right) q(\boldsymbol{v} \mid \lambda)}\right. \\
\left.+\frac{1}{2}\langle\ln \lambda\rangle_{q(\lambda)}+\left\langle\ln \theta_{i}\right\rangle_{q(\boldsymbol{\theta})}\right)+C
\end{array}
$$

(A3) 式は (3) 式の対数の形になっている. すなわち $q(\boldsymbol{S})$ はカテゴリー分布で与えられることを意味している。こ こで, $\hat{\lambda}=\langle\lambda\rangle_{q(\lambda)}$ であり，付録 4. で導出する $q(\lambda)$ を用 いることで $(20)$ 式として得られる. 同様に，付録 3.〜 付録 5. で導出する $q(\boldsymbol{f}), q\left(v_{i} \mid \lambda\right), q(\theta)$ を用いることで $\left\langle\ln \theta_{i}\right\rangle_{q(\boldsymbol{\theta})}$ および $\left\langle\left(y_{n}-f_{n}-v_{i}\right)^{2}\right\rangle_{q\left(f_{n}\right) q(\boldsymbol{v} \mid \lambda)}$ は $(22)$ 式お よび $(24)$ 式として得られる. 以上より, $q(\boldsymbol{S})$ は $(14)$ 式 で与えられる。このとき $s_{n, i}$ の期待值はカテゴリー分布 の定義式より次式として得られる.

$$
\left\langle s_{n, i}\right\rangle_{q\left(s_{n}\right)}=\hat{\eta}_{n, i}
$$

\section{付録 3. $q(\boldsymbol{f})$ の導出}

$f$ の項以外は定数とみなすと (A2) 式より,

$$
\begin{array}{r}
\ln q(\boldsymbol{f}) \\
=\langle\ln p(\boldsymbol{y} \mid \boldsymbol{f}, \boldsymbol{S}, \boldsymbol{v}, \lambda)\rangle_{q(\boldsymbol{S}) q(\boldsymbol{v}, \lambda)} \\
+\langle\ln p(\boldsymbol{f})\rangle_{q(\boldsymbol{f})}+C \\
=-\frac{\hat{\lambda}}{2} \sum_{n=1}^{N} \sum_{i=1}^{N_{k}} \hat{\eta}_{n, i}\left(f_{n}^{2}-2 f_{n}\left(y_{n}-\hat{v}_{i}\right)\right) \\
-\frac{1}{2} \boldsymbol{f}^{T} \boldsymbol{K} \boldsymbol{f}+C
\end{array}
$$

ここで, $\hat{v}_{i}=\left\langle v_{i}\right\rangle_{q\left(v_{i} \mid \lambda\right)}$ であり，付録 4. で導出する $q\left(v_{i} \mid \lambda\right)$ を用いることで $\hat{v}_{i}=\frac{\sum_{n=1}^{N} \hat{\eta}_{n, i}\left(y_{n}-\hat{y}_{n}\right)+\beta \mu_{i}}{\hat{\beta}_{i}}$ で与え られる，いま，次式を定義する．

$$
\bar{f}_{n}:=\hat{\lambda} \sum_{i=1}^{N_{k}} \hat{\eta}_{n, i}\left(y_{n}-\hat{v}_{i}\right), \quad \hat{\boldsymbol{K}}:=\left(\hat{\lambda} \boldsymbol{I}+\boldsymbol{K}^{-1}\right)^{-1}
$$

このとき, $\sum_{i=1}^{N_{k}} \hat{\eta}_{n, i}=1$ であることに注意すると, 次式 が成り立つ。

$$
\begin{aligned}
\ln q(\boldsymbol{f}) & =-\frac{\hat{\lambda}}{2} \sum_{n=1}^{N}\left(f_{n}^{2}-2 f_{n} \bar{f}_{n}\right)-\frac{1}{2} \boldsymbol{f}^{T} \boldsymbol{K} \boldsymbol{f}+C \\
& =-\frac{1}{2}(\boldsymbol{f}-\hat{\boldsymbol{K}} \overline{\boldsymbol{f}})^{T} \hat{\boldsymbol{K}}^{-1}(\boldsymbol{f}-\hat{\boldsymbol{K}} \overline{\boldsymbol{f}})+C
\end{aligned}
$$

これは (1) 式の対数の形になっており, $q(\boldsymbol{f})$ は正規分布 で与えられることを意味している。よって, $q(\boldsymbol{f})$ は $(15)$ 式で与えられる。 また，このとき次式が得られる。

$$
\begin{aligned}
\left\langle\left(y_{n}-f_{n}\right)^{2}\right\rangle_{q\left(f_{n}\right)} & =y_{n}^{2}-2 y_{n}\left\langle f_{n}\right\rangle_{q\left(f_{n}\right)}+\left\langle f_{n}^{2}\right\rangle_{q\left(f_{n}\right)} \\
& =y_{n}^{2}-2 y_{n} \hat{f}_{n}+\hat{f}_{n}^{2}+\hat{K}_{n n}
\end{aligned}
$$

すなわち (23) 式が成り立つ.

付録 4. $q(\boldsymbol{v}, \lambda)$ の導出

$\boldsymbol{v}$ および入の項以外は定数とみなすと (A2) 式より,

$$
\begin{array}{r}
\ln q(\boldsymbol{v}, \lambda) \\
=\sum_{i=1}^{N_{k}}\left(\sum_{n=1}^{N}\left\langle\ln p\left(y_{n} \mid f_{n}, \boldsymbol{s}_{n}, v_{i}, \lambda\right)\right\rangle_{q\left(f_{n}\right) q\left(s_{n}\right)}\right. \\
\left.+\ln p\left(v_{i} \mid \lambda\right)\right)+\ln p(\lambda)+C \\
=\sum_{i=1}^{N_{k}}\left(-\frac{\lambda \hat{\beta}_{i}}{2} v_{i}^{2}+\lambda \hat{\beta}_{i} v_{i} \hat{v}_{i}-\frac{\lambda \hat{\beta}_{i}}{2} \mu_{i}^{2}\right. \\
-\frac{\lambda}{2} \sum_{n=1}^{N} \hat{\eta}_{n, i}\left\langle\left(y_{n}-f_{n}\right)^{2}\right\rangle_{q\left(f_{n}\right)} \\
\left.+\left(\frac{1}{2} \sum_{n=1}^{N} \hat{\eta}_{n, i}+1\right) \ln \lambda\right) \\
+(a-1) \ln \lambda-b \lambda+C
\end{array}
$$

ここで $v_{i}$ の項のみに着目し，それ以外を定数とみなす と, $\boldsymbol{v}$ の分布は $N_{k}$ 個の独立な分布に分解できることが わかる。すなわち,

$$
\ln q\left(v_{i} \mid \lambda\right)=-\frac{\lambda \hat{\beta}_{i}}{2}\left(v_{i}^{2}-2 v_{i} \hat{v}_{i}\right)+C
$$

これは (1) 式の対数の形になっており, $q\left(v_{i} \mid \lambda\right)$ が正規分 布で与えられることを意味している。よって, $q\left(v_{i} \mid \lambda\right)$ は (18) 式で与えられる。このとき $\lambda$ に関する項も含めた (18) 式の対数は, 次式として記述し直すことができる.

$$
\ln q\left(v_{i} \mid \lambda\right)=-\frac{\lambda \hat{\beta}_{i}}{2}\left(v_{i}^{2}-2 v_{i} \hat{v}_{i}+\hat{v}_{i}^{2}\right)+\frac{1}{2} \ln \lambda+C
$$

条件付き確率の定義より $\ln q(\lambda)=\ln q(\boldsymbol{v}, \lambda)-\ln q(\boldsymbol{v} \mid \lambda)$ が成り立つことから次式が得られる.

$$
\begin{aligned}
& \ln q(\lambda)=\ln q(\boldsymbol{v}, \lambda)-\sum_{i=1}^{N_{k}} \ln q\left(v_{i} \mid \lambda\right) \\
&=\left(\frac{N}{2}+a-1\right) \ln \lambda-\left\{\frac { 1 } { 2 } \left(\sum_{n=1}^{N}\left\langle\left(y_{n}-f_{n}\right)^{2}\right\rangle_{q\left(f_{n}\right)}\right.\right. \\
&\left.\left.+\sum_{i=1}^{N_{k}}\left(\beta \mu_{i}^{2}-\hat{\beta}_{i} \hat{v}_{i}^{2}\right)\right)+b\right\} \lambda+C
\end{aligned}
$$

これは (5) 式の対数の形になっており, $q(\lambda)$ がガンマ分 布で与えられることを意味している，よって， $q(\lambda)$ は (19) 式で与えられる。また，このとき次式が成り立つ。

$$
\langle\lambda\rangle_{q(\lambda)}=\frac{\hat{a}}{\hat{b}}, \quad\langle\ln \lambda\rangle_{q(\lambda)}=\psi(\hat{a})-\ln \hat{b}
$$

すなわち (20), (21) 式が成り立つ. 
得られた $q\left(v_{i} \mid \lambda\right)$ と付録 $\mathbf{3}$.で得られた $q(\boldsymbol{f})$ を用いる ことで次式が得られる。

$$
\begin{aligned}
& \left\langle\left(y_{n}-f_{n}-v_{i}\right)^{2}\right\rangle_{q\left(f_{n}\right) q\left(v_{i} \mid \lambda\right)} \\
& =\left\langle\left(y_{n}-f_{n}\right)^{2}-2 v_{i}\left(y_{n}-f_{n}\right)+v_{i}^{2}\right\rangle_{q\left(f_{n}\right) q\left(v_{i} \mid \lambda\right)} \\
& =\left\langle\left(y_{n}-f_{n}\right)^{2}\right\rangle_{q\left(f_{n}\right)}-2 \hat{v}_{i}\left(y_{n}-\hat{f}_{n}\right)+\hat{v}_{i}^{2}+\left(\hat{\beta}_{i} \lambda\right)^{-1}
\end{aligned}
$$

すなわち (24) 式が成り立つ。

付録 5. $q(\boldsymbol{\theta})$ の導出

$\boldsymbol{\theta}$ の項以外は定数とみなすと $(\mathrm{A} 2)$ 式より,

$$
\begin{aligned}
& \ln q(\boldsymbol{\theta}) \\
& =\langle\ln p(\boldsymbol{S} \mid \boldsymbol{\theta})\rangle_{q(\boldsymbol{f}) q(\boldsymbol{S})}+\ln p(\boldsymbol{\theta})+C \\
& =\sum_{i=1}^{N_{k}}\left(\sum_{n=1}^{N}\left\langle s_{n, i}\right\rangle_{q(\boldsymbol{S})}+\left(\alpha_{i}-1\right)\right) \ln \theta_{i}+C
\end{aligned}
$$

これは (4) 式の対数の形になっており, $q(\boldsymbol{\theta})$ ディリクレ 分布で与えられることを意味している.よって, $q(\boldsymbol{\theta})$ は (17) 式で与えられる。また，このとき次式が成り立つ.

$$
\begin{aligned}
\left\langle\theta_{i}\right\rangle_{q(\boldsymbol{\theta})} & =\frac{\hat{\alpha}_{i}}{\sum_{i=1}^{N_{k}} \hat{\alpha}_{i}} \\
\left\langle\ln \theta_{i}\right\rangle_{q(\boldsymbol{\theta})} & =\psi\left(\hat{\alpha}_{i}\right)-\psi\left(\sum_{i=1}^{N_{k}} \hat{\alpha}_{i}\right)
\end{aligned}
$$

すなわち $(22)$ 式が成り立つ。

\section{付録 6. ELBO の導出}

ELBO の定義式より，

$$
\begin{aligned}
& \mathcal{L}[q]= \int(\boldsymbol{f}) q(\boldsymbol{S}) q(\boldsymbol{v}, \lambda) q(\boldsymbol{\theta}) \\
& \times \ln \frac{p(\boldsymbol{f}, \boldsymbol{S}, \boldsymbol{v}, \lambda, \boldsymbol{\theta}, \mathcal{D})}{q(\boldsymbol{f}) q(\boldsymbol{S}) q(\boldsymbol{v}, \lambda) q(\boldsymbol{\theta})} d \boldsymbol{f} d \boldsymbol{S} d \boldsymbol{v} d \lambda d \boldsymbol{\theta} \\
&=\sum_{n=1}^{N}\left\langle\ln p\left(\boldsymbol{y}_{n} \mid \boldsymbol{f}_{n}, \boldsymbol{s}_{n}, \boldsymbol{v}, \lambda\right)\right\rangle_{q(\boldsymbol{f}) q(\boldsymbol{S}) q(\boldsymbol{v}, \lambda)} \\
&-\sum_{n=1}^{N}\left\{\left\langle\ln q\left(\boldsymbol{s}_{n}\right)\right\rangle_{\left.q\left(\boldsymbol{s}_{n}\right)\right)}-\left\langle\ln p\left(\boldsymbol{s}_{n} \mid \boldsymbol{\theta}\right)\right\rangle_{q\left(\boldsymbol{s}_{n}\right) q(\boldsymbol{\theta})}\right\} \\
&-\mathrm{KL}[q(\boldsymbol{f}) \| p(\boldsymbol{f})]-\mathrm{KL}[q(\boldsymbol{v}, \lambda) \| p(\boldsymbol{b}, \lambda)] \\
&-\mathrm{KL}[q(\boldsymbol{\theta}) \| p(\boldsymbol{\theta})]
\end{aligned}
$$

ここで,

$$
\begin{aligned}
& \left\langle\ln p\left(\boldsymbol{y}_{n} \mid \boldsymbol{f}_{n}, \boldsymbol{s}_{n}, \boldsymbol{v}, \lambda\right)\right\rangle_{q(\boldsymbol{f}) q(\boldsymbol{S}) q(\boldsymbol{v}, \lambda)} \\
& =\sum_{i=1}^{N_{k}}\left\langle s_{n, i}\right\rangle_{q\left(\boldsymbol{s}_{n}\right)}\left(-\frac{\hat{\lambda}}{2}\left\langle\left(y_{n}-f_{n}-v_{i}\right)^{2}\right\rangle_{q\left(f_{n}\right) q\left(v_{i} \mid \lambda\right)}\right. \\
& \left.\quad+\frac{1}{2}\langle\ln \lambda\rangle_{q(\lambda)}+\frac{1}{2} \ln \pi\right) \\
& \left\langle\ln q\left(\boldsymbol{s}_{n}\right)\right\rangle_{\left.q\left(\boldsymbol{s}_{n}\right)\right)}-\left\langle\ln p\left(\boldsymbol{s}_{n} \mid \boldsymbol{\theta}\right)\right\rangle_{q\left(\boldsymbol{s}_{n}\right) q(\boldsymbol{\theta})} \\
& \quad=\sum_{i=1}^{N_{k}}\left\{\left\langle s_{n, i}\right\rangle_{q\left(\boldsymbol{s}_{n}\right)}\left(\ln \hat{\eta}_{n, i}-\left\langle\ln \theta_{i}\right\rangle_{q\left(\boldsymbol{s}_{n}\right)}\right)\right\}
\end{aligned}
$$

$$
\begin{aligned}
\operatorname{KL} & {[q(\boldsymbol{f}) \| p(\boldsymbol{f})] } \\
& =\frac{1}{2}\left\{\operatorname{Tr}\left(\left(\hat{\boldsymbol{f}} \hat{\boldsymbol{f}}^{T}+\hat{\boldsymbol{K}}\right) \boldsymbol{K}^{-1}\right)+\ln \frac{|\boldsymbol{K}|}{|\hat{\boldsymbol{K}}|}-N\right\}
\end{aligned}
$$

$$
\begin{aligned}
& \mathrm{KL}[q(\boldsymbol{v}, \lambda) \| p(\boldsymbol{v}, \lambda)] \\
& =\mathrm{KL}[q(\lambda) \| p(\lambda)]+\sum_{i=1}^{N_{k}}\left\langle\mathrm{KL}\left[q\left(v_{i} \mid \lambda\right) \| p\left(v_{i} \mid \lambda\right)\right]\right\rangle_{q(\lambda)} \\
& \mathrm{KL}[q(\boldsymbol{\theta}) \| p(\boldsymbol{\theta})]=\sum_{i=1}^{N_{k}}\left(\hat{\alpha}_{i}-\alpha_{i}\right)\left\langle\ln \theta_{i}\right\rangle_{q(\boldsymbol{\theta})}+\ln \frac{C_{D}(\hat{\boldsymbol{\alpha}})}{C_{D}(\boldsymbol{\alpha})}
\end{aligned}
$$

であり，

$$
\begin{aligned}
& \operatorname{KL}[q(\lambda) \| p(\lambda)] \\
& =(\hat{a}-a)\langle\ln \lambda\rangle_{q(\lambda)}-(\hat{b}-b) \hat{\lambda}+\ln \frac{C_{G}(\hat{a}, \hat{b})}{C_{G}(a, b)} \\
& \left\langle\operatorname{KL}\left[q\left(v_{i} \mid \lambda\right) \| p\left(v_{i} \mid \lambda\right)\right]\right\rangle_{q(\lambda)} \hat{\beta}_{i}^{-1} \\
& \quad=\frac{1}{2}\left\{\frac{\left.\hat{\lambda}\left(\mu_{i}-\hat{v}_{i}\right)^{2}+\ln \frac{\hat{\beta}_{i}}{\beta}-1\right\}}{\beta^{-1}}\right\}
\end{aligned}
$$

である。

\section{著者 略歴}

\section{金毕泰慜 (正会員)}

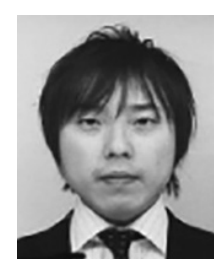

2005 年東京工業大学大学院理工学研究 科機械制御システム専攻修士課程修了。同 年（株）リコー入社，2007年（地独）東京 都立産業技術研究センター入所, 2014 年 東京工業大学大学院理工学研究科機械制御 システム専攻博士後期課程修了．現在，東 京都立産業技術研究センター情報技術グループ上席研究員. 状態推定理論, ベイズ推論, 統計モデリングに関する研究に 従事. 博士 (工学)．2020 年システム制御情報学会学会賞論 文賞受賞. IEEE, 計測自動制御学会, 電気学会, 各会員.

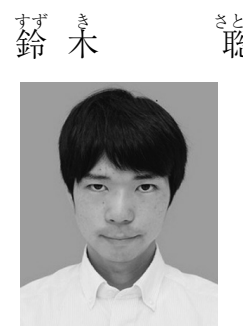

2018 年電気通信大学情報理工学研究科 情報・ネットワーク工学専攻修士課程修 了. 同年（地独）東京都立産業技術研究セ ンター入所，現在，東京都立産業技術研究 センター情報技術グループ研究員. 統計的 信号処理やソフトセンサに関する研究に従 事. 修士 (工学).

\section{只等康晴 (正会員)}

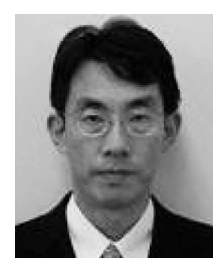

2002 年名古屋大学大学院工学研究科計 算理工学専攻博士課程修了. 現在, (地独) 東京都立産業技術研究センター主席研究 員. 知能化技術, 非線形モデリング, 組込 みシステムの信頼性向上に関する研究開発 に従事. 博士 (工学)。2020年システム制 御情報学会学会賞論文賞受賞. 計測自動制御学会, 電気学会, 日本知能情報ファジィ学会, 各会員. 